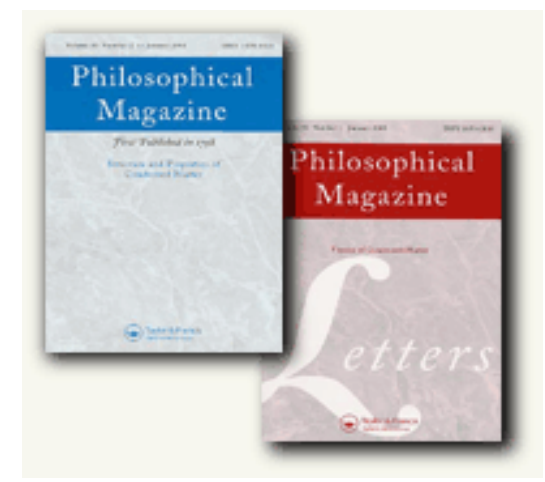

\title{
Influence of Impurities on the Fracture Behaviour of Tungsten
}

\begin{tabular}{|r|l|}
\hline Journal: & Philosophical Magazine \& Philosophical Magazine Letters \\
\hline Manuscript ID: & TPHM-10-Jul-0342.R1 \\
\hline Journal Selection: & Philosophical Magazine \\
\hline Dute Submitted by the & 29-Dec-2010 \\
\hline Complete List of Authors: & $\begin{array}{l}\text { Gludovatz, Bernd; Austrian Academy of Sciences, Erich Schmid } \\
\text { Institute of Materials Science } \\
\text { Wurster, Stefan; Austrian Academy of Sciences, Erich Schmid } \\
\text { Institute of Materials Science } \\
\text { Weingärtner, Tobias; Karlsruhe Institute of Technology, Institute for } \\
\text { Material Research I } \\
\text { Hoffmann, Andreas; Plansee Metall GmbH. } \\
\text { Pippan, Reinhard; Austrian Academy of Sciences, Erich Schmid } \\
\text { Institute of Materials Science }\end{array}$ \\
\hline Keywords: & $\begin{array}{l}\text { AES, grain boundaries, grain size, brittle materials, fracture, } \\
\text { microstructure, tungsten, cracks }\end{array}$ \\
\hline Keywords (user supplied): & \begin{tabular}{l} 
impurities, intergranular fracture, transgranular fracture \\
\hline
\end{tabular} \\
\hline
\end{tabular}

\section{SCHOLARONE ${ }^{\text {m }}$ Manuscripts}




\title{
RESEARCH ARTICLE
}

\section{Influence of Impurities on the Fracture Behaviour of Tungsten}

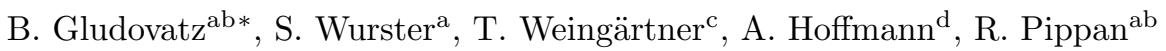 \\ ${ }^{\mathrm{a}}$ Erich Schmid Institute of Materials Science, Austrian Academy of Sciences, Jahnstrasse \\ 12, A-8700 Leoben, Austria; ${ }^{\mathrm{b}}$ Christian Doppler Laboratory for Local Analysis of \\ Deformation and Fracture, Jahnstrasse 12, A-8700 Leoben, Austria; ${ }^{\mathrm{c}}$ Karlsruhe Institute \\ of Technology, Institute for Material Research I, Herrmann-von-Helmholtz-Platz 1, \\ D-76344 Eggenstein-Leopoldshafen, Germany; ${ }^{\mathrm{d}}$ Plansee Metall GmbH, A-6600 Reutte, \\ Austria \\ (v4.5 released May 2010)
}

\begin{abstract}
Ten tungsten materials with different impurity concentrations and different microstructures have been investigated by Auger electron spectroscopy and scanning electron microscopy with respect to their fracture behaviour. For almost all samples both inter- and transgranular fracture are observed, the proportion of each type varies. Due to the difference in their impurity content and grain boundary area, a large variation in the grain boundary impurities can be expected. By analysing the fracture surfaces the effect of grain boundary impurities, especially phosphorous and oxygen, on the fracture resistance of the boundaries was determined. The results indicate that for the analysed tungsten materials grain boundary impurities do not have a significant influence on the fracture resistance of the boundaries. Other factors such as the size and shape of the grains, the amount of deformation and therefore the density of dislocations within the grains have a greater impact on the fracture behaviour of tungsten.
\end{abstract}

Keywords: impurities; Auger electron spectroscopy; grain boundaries; grain size; grain shape; brittle; intergranular fracture; transgranular fracture

\section{Introduction}

Tungsten-based materials show the characteristic change in fracture behaviour from brittle at low temperatures to ductile at high temperatures. Experiments indicate that grain size, texture, chemical composition, grain boundary (GB) segregation and dislocation density seem to have a large effect on the fracture toughness especially below the ductile to brittle transition temperature (DBTT) 1]. In contrary to many other bcc metals, in tungsten a combination of trans- and intergranular fracture is usually observed, although the area fraction of each type varies.

Over the last fifty years numerous investigations have been carried out with the aim of improving the understanding of the fracture behaviour. Most studies relating to the ductility of tungsten materials were done in the fifties, sixties and few in the seventies [2 7. GB impurities, which were thought to be one of the main causes of intergranular fracture, were investigated to determine the effect of particularly carbon $(\mathrm{C})$, oxygen $(\mathrm{O})$, potassium $(\mathrm{K})$ and phosphorous $(\mathrm{P})$ [8-10]. Joshi and Stein 9 investigated the segregation of $\mathrm{O}$ to the GBs of tungsten in the seventies. By adding various amounts of $\mathrm{C}$ they wanted to show an interaction of

*Corresponding author. Email: bernd.gludovatz@unileoben.ac.at 
the two elements to better understand the brittle behaviour of the material. As there was no chemical reaction of $\mathrm{C}$ and $\mathrm{O}$, they suggested that $\mathrm{O}$ is not the cause for the embrittlement of tungsten. However, Auger spectroscopy analyses showed the segregation of $\mathrm{P}$ to the GBs which was thought to be the main cause for the brittle behaviour of tungsten. The amount of segregation was dependent upon the grain-size - the larger the grain size, the greater the concentration of $\mathrm{P}$ at the GB and the higher the embrittlement. Values concerning the amounts of impurities contained in the investigated materials are not given in this study.

In the eighties Tran-Huu-Loi et al. [11 investigated three different tungsten materials with the main impurities as follows: material A) $20 \mathrm{ppm} \mathrm{C,} 3 \mathrm{ppm} \mathrm{O}$, $60 \mathrm{ppm} \mathrm{K}$ / material B) $30 \mathrm{ppm} \mathrm{C,} 2 \mathrm{ppm} \mathrm{K,} 20 \mathrm{ppm} \mathrm{P} \mathrm{/} \mathrm{material} \mathrm{C)} 30 \mathrm{ppm}$ C, 30 ppm O, 10 ppm K, 50 ppm P. All materials had equiaxed microstructures and where investigated by impact tests, scanning electron microscopy and Auger spectroscopy in the temperature range $-196^{\circ} \mathrm{C}$ to $1000^{\circ} \mathrm{C}$. Below DBTT various proportions of inter- and transgranular fracture were observed while increasing temperature and increasing $\mathrm{P}$ concentration lead to an increasing amount of intergranular fracture.

Danninger et al. [12] carried out similar investigations on the role of $\mathrm{P}$ by secondary ion mass spectroscopy (SIMS). He concluded that an average content of 20-40 ppm P, like it was standard in technically produced tungsten heavy alloys at this time (W powders were mixed with $\mathrm{Ni}$ and $\mathrm{Fe}$ powders), does not influence the fracture behaviour of tungsten and only higher concentrations can increase the embrittlement.

Due to the improvement in industrial production nowadays $\mathrm{W}$ materials contain significantly lower $\mathrm{P}$ and $\mathrm{O}$ contents. Nevertheless, the frequently observed GB fracture is often associated with the impurity content. By discussing the limits of impurities it is important not only to relay on certain maxima of ppm, but to take into account the grain size or in other words the grain boundary area and how the impurities are distributed on the GBs.

To better quantify the influence of impurities in W on grain boundary fracture, a standard technical $\mathrm{W}$, a high purity $\mathrm{W}$ and a $\mathrm{W}$ material of high impurity content, with different grain sizes, grain shapes and dislocation structures are investigated with respect to grain boundary fracture.

Technically pure W manufactured by Plansee Metall GmbH. contains typical impurity concentrations as shown in table 1. The first line shows the maximum concentration they guarantee not to exceed while the second line gives the average impurity concentrations. This commercially available material was either used purchased as is or changed in its microstructure, samples made from these materials will be subsequently referred to as technically pure. An additional chemical analysis on $\mathrm{O}, \mathrm{P}$ and $\mathrm{S}$ was made on these materials which results are shown in the third line of table 1 . Samples from these technically pure materials were also compared to materials with an either much lower content of impurities or a much higher content of impurities.

Nowadays, Auger electron spectrometers with point resolutions of less than a micron can be much better focused on the areas of interest, however, the sensitivities of spectrometers did not improve as much as the ability to focus the electron beam. Nevertheless, the ability of Auger spectrometers to detect fractions of monolayers of elements on a surface, together with a good focused electron beam, is a useful tool to investigate GB impurities of large grained as well as the fine and ultra fine grained materials to improve the understanding of the effect of GB impurities like $\mathrm{O}$ or $\mathrm{P}$ in tungsten. 


\section{Materials and experimental methods}

An investigation of the effect of impurity concentrations on the fracture behaviour of tungsten materials was done by analyses of fracture surfaces by Auger electron spectroscopy (AES) and scanning electron microscopy (SEM). The fracture behaviour of materials purchased as-is was analysed and compared with the fracture behaviour of materials processed to different microstructures. Changing microstructures with an either higher or smaller area of grain boundaries (GBs) lead to a changing fraction of the impurity concentration on the GBs. If there is an influence of the impurities on the fracture behaviour, this should become obvious by a changing amount of inter- and transgranular fracture.

A tungsten single crystal, with a significantly smaller impurity concentration, was severely plastically deformed (SPD) by a high pressure torsion (HPT) tool [13, 14, to generate an ultra-fine grained (UFG) polycrystal and subsequent annealing resulted in a coarsening of the grain structure. Its fracture behaviour was additionally taken into comparison.

Table 2 summarizes the different tungsten samples investigated with their manufacturing condition and average grain size. Three of these samples were used as-is, purchased from Plansee Metall GmbH. They are described as follows: rolled tungsten rods $\left(\mathrm{W}_{\text {rolled }}\right)$ with an elongated grain structure - the grains have an average diameter of about $31 \mu \mathrm{m}$ in the cross section (figure 1-b) and an average length of about $121 \mu \mathrm{m}$ (figure 1-a) which gives an aspect ratio of $\mathrm{d} / \mathrm{l} \sim 0.26$; sintered tungsten $\left(\mathrm{W}_{\text {sintered }}\right)$ with an average grain size of $25 \mu \mathrm{m}$ (figure 1-d) and hipped tungsten ( $\mathrm{W}_{\text {hipped }}$ ) with a similar grain size but a bimodal grain size distribution (figure 1-e). The sintered and hipped materials have a porosity of about $6 \%$ and $4 \%$, respectively. The sintered tungsten has the same impurity concentration as the technically pure tungsten, while the hipped tungsten material has a higher concentration of impurities, in this case a significantly higher oxygen content, $118 \mu \mathrm{g} / \mathrm{g}$. In order to investigate the effect of impurities on grain boundary fracture, tungsten with different grain sizes was produced from the technically pure and single crystalline materials. This technical variation was achieved either by simply recrystallizing the pure material or by applying SPD to the materials. Two samples were used directly following SPD, all other samples were additionally heat treated. The technically pure tungsten was recrystallized at $2000^{\circ} \mathrm{C}$ for an hour leading to an average grain size of $\sim 95 \mu \mathrm{m}$ referred to as $\mathrm{W}_{\text {recryst }}$ (figure 1 -c). The ultra-fine grained (UFG) samples, both with an average grain size of $\sim 300 \mathrm{~nm}$, were produced from a tungsten single crystal (UFG-W $\mathrm{W}^{\text {sc }}$ / figure 1-f) and a technically pure tungsten (UFG-W / figure 1-j) using HPT. In each case, disc-shaped samples with a diameter of $8 \mathrm{~mm}$ and a thickness of $0.8 \mathrm{~mm}$ were deformed to 4 revolutions, corresponding to an equivalent von Mises strain, $\epsilon_{v m} \approx 64$, at a temperature of $400^{\circ} \mathrm{C}$ and a hydrostatic pressure of $\sim 8 \mathrm{GPa}$. Further UFG samples were subsequently heat treated at $600^{\circ} \mathrm{C}, 800^{\circ} \mathrm{C}$ or $1200^{\circ} \mathrm{C}$ in a vacuum furnace for one hour to produce coarser, recrystallized microstructures [15]. After recrystallization, the $\mathrm{W}_{1200}$ (figure 1-k) had a grain size of $\sim 4 \mu \mathrm{m}$ while the $\mathrm{W}_{600}^{\mathrm{sc}}$ (figure $1-\mathrm{g}$ ), $\mathrm{W}_{800}^{s c}$ (figure 1 - $\mathrm{h}$ ) and $\mathrm{W}_{1200}^{s c}$ (figure 1-i) had grain sizes of $\sim 300 \mathrm{~nm}, \sim 8 \mu \mathrm{m}$ and $\sim 92 \mu \mathrm{m}$, respectively. The significant effect of the impurities is clearly visible in the different recrystallization and grain growth behaviour. Impurity contents of samples prepared from single crystals will be subsequently referred to as ultra low. Table 2 additionally shows the sum of the length of high angle grain boundaries per $1 \mu \mathrm{m}^{2}$ area, $l_{\mathrm{GB}} / \mathrm{A}$, which is dependent on the size and shape of the grains. The values were determined using SEM fractographs together with the imaging software package analySIS [16]. 
For each material tested, a 3-point bending beam-like specimens was machined, the samples vary in their dimensions due to different geometries of the raw materials. The beams were notched with a diamond wire followed by a razor blade sharpening. The specimens were fractured at room temperature in an ultra high vacuum (UHV) chamber of a PHI 680 Auger Nanoprobe, a field emission Auger microprobe. The fracture surface impurities were analysed by Auger spectrometry at $10 \mathrm{kV} / 20 \mathrm{nA}$ immediately after fracturing the specimens at a vacuum between $1 \times 10^{-9}$ mbar and $1 \times 10^{-10}$ mbar and the fracture surface images were taken either with this microscope or with a Zeiss LEO 982 field-emission scanning electron microscope (FE-SEM) after the analyses.

\section{Results}

Microscopic observations of the fracture surfaces in figure 1 show two types of brittle fracture: intergranular and transgranular fracture. While the ratio of intergranular to transgranular fracture varies significantly, every specimen shows fracture along the GBs as well as cleavage fracture.

\subsection{Samples with an ultra low impurity concentration}

The four materials produced from the tungsten single crystal (W-SC) exhibit no impurities at the GBs within the resolution limit of the used Auger electron spectroscopy (AES) device; namely UFG-W $\mathrm{W}^{\mathrm{sc}}, \mathrm{W}_{600}^{\mathrm{sc}}, \mathrm{W}_{800}^{\mathrm{sc}}$ and $\mathrm{W}_{1200}^{\mathrm{sc}}$ (figure $1 \mathrm{f}-\mathrm{i}$ ). The Auger-spectrum of one of these samples, $\mathrm{W}_{1200}^{\mathrm{sc}}$, can be seen in figure $2 \mathrm{a}$ - a typical spectrum for tungsten [20] - where, apart from a very small O-peak at $\sim 510 \mathrm{eV}$, the spectra are clean and similar. The samples were cleaned before putting them on the fracture stage in the UHV chamber and fracturing them within the chamber. After that, the samples were moved from the fracture position to the analyse position and the spectra were recorded. As the time between fracturing and analysing was relatively short, the detected $\mathrm{O}$ cannot be adsorbed on the new fracture surface from the remaining gas in the vacuum. Small O peaks like shown in figure 2-a are sometimes visible on different samples and differ in their heights. If they appear, they are usually visible at GBs as well as on cleaved grains which can be found in the high purity $\mathrm{W}$ as in this case. Therefore, it can be concluded that this $\mathrm{O}$ peak (only when there is no difference in the peak height between the spectra of a GB and the cleaved grains) is a consequence of a desorption process from some other surfaces of the sample or the sample holder during fracture or the sample manipulation and an adsorption process on the newly generated fracture surface which has a high sticking coefficient.

While the percentage of intergranular fracture is almost $100 \%$ for the UFG-W ${ }^{\mathrm{sc}}$ and the $\mathrm{W}_{600}^{\mathrm{sc}}$ (crack propagation front tangential to the axis of the HPT specimen [17]), the other recrystallized samples, $\mathrm{W}_{800}^{\mathrm{sc}}$ and $\mathrm{W}_{1200}^{\mathrm{sc}}$, show increasing transgranular fracture with increasing recrystallization temperature as shown in table 2 .

\subsection{Technically pure tungsten samples}

Compared to the nearly impurity-free materials, $\mathrm{W}_{\text {sintered }}, \mathrm{W}_{\text {rolled }}$ and $\mathrm{W}_{\text {recryst }}$ as well as UFG-W and $\mathrm{W}^{1200}$ contain the typical impurities shown in table 1 . While $\mathrm{W}_{\text {sintered }}, \mathrm{W}_{1200}$ and UFG-W (in tangential direction) are dominated by 
intergranular fracture, $\mathrm{W}_{\text {recryst }}$, with an average grain size of $95.2 \pm 35.7 \mu \mathrm{m}$, shows an increased amount of transgranular fracture. $\mathrm{W}_{\text {rolled }}$ has a mixture of both fracture types with a higher amount of grain boundary fracture along the axis and cleavage fracture is dominating the cross section of the rods.

Figure 2-b shows the AES-spectrum of UFG-W. Except for the difference in the O-peak, the spectrum is basically the same asthe $\mathrm{W}_{1200}^{\mathrm{sc}}$ spectrum in figure 2 -a. In contrary, $\mathrm{P}$ (peak at $\sim 123 \mathrm{eV}$ ) was the only detected impurity of $\mathrm{W}_{\text {rolled }}$. It was found on almost all GBs which can clearly be seen in the AES-spectrum of figure 2 -c. $\mathrm{W}_{\text {recryst }}$ and $\mathrm{W}_{1200}$ are materials with quite different grain sizes, however in both cases most GBs are covered with phosphorous. This can be seen for example in figure 3-b, an overlay of a P-mapping over the corresponding fracture surface of $\mathrm{W}_{\text {recryst }}$. Figure 3-a shows the additional AES spectrum of a GB, indicating $\mathrm{P}$ as the only impurity. Another P-mapping as an overlay on the SEM image of the fracture surface of $\mathrm{W}_{\text {sintered }}$ can be seen in figure $4 . \mathrm{P}$ is clearly visible concentrated in the sinter pores.

Despite most GBs of $\mathrm{W}_{\text {rolled }}, \mathrm{W}_{\text {recryst }}$ and $\mathrm{W}_{1200}$ being covered with $\mathrm{P}$, the highest fraction of cleavage fracture is found in $\mathrm{W}_{\text {rolled }}$. $\mathrm{W}_{\text {recryst }}$ and $\mathrm{W}_{1200}$ show a higher fraction of intergranular fracture, while $\mathrm{W}_{\text {sintered }}$ and UFG-W (in tangential direction), materials with a relatively low impurity concentration at the GBs, show most intergranular fracture (2).

\subsection{Samples with a high impurity concentration}

$\mathrm{W}_{\text {hipped }}$ contains a much higher amount of impurities, as already described in section 2. An O-mapping as an overlay on the corresponding SEM image of the fracture surface is shown in figure 5, showing that oxygen covers almost all GBs. The dominant fracture type is intergranular fracture which is clear in figure 1-e, however, the amount of fracture along the GBs is smaller than for $\mathrm{W}_{\text {sintered }}$ as shown in table 2 .

\section{Discussion}

\subsection{Influence of impurities}

Impurities like $\mathrm{O}, \mathrm{P}$ or $\mathrm{C}$ generally cover high angle GBs as they are not soluble in tungsten [21]. A varying amount of GBs obtained by either just recrystallizing a pre-deformed material or a combination of SPD and recrystallization, as it was applied in this study, leads to a varying impurity concentration on the GBs. The shear deformation during HPT distributes the impurities on the increasing density of high angle GBs and as a result the concentration of impurities per GB area should decrease. Materials produced from the single crystal have very low impurity concentrations and the density of GBs does hardly influence the material with respect to the impurity concentration per GB area especially at smaller grain sizes. Technically pure tungsten materials are changing their impurity concentrations per GB area with their GB proportions. This can also be seen in figure 2 -b, the AES data of UFG-W. The material has a very high density of GBs, impurities are extremely wide distributed and therefore the spectrum looks very similar to $\mathrm{UFG}^{\mathrm{Sc}}$ (figure 2-a). Although impurities were not found at the GBs of these materials, cracks propagate inter- and transgranularly which is more dependent on the size and shape of the grains than on the concentration of impurities on the grain boundaries. Similar effects have also been seen in iron [17]. 
Most samples were recrystallized after the HPT deformation, thus having a lower density of GBs and therefore a higher concentration of impurities on the GBs compared to the UFG samples. $\mathrm{W}_{1200}$ and $\mathrm{W}_{\text {recryst }}$ are both materials with a recrystallized microstructure as shown in figure 1-c and 1-k, respectively. Despite the smaller grain size and the lower GB impurity concentration of $\mathrm{W}_{1200}$ compared to $\mathrm{W}_{\text {recryst }}, \mathrm{W}_{1200}$ shows the higher fraction of intergranular fracture which can be seen in table 2. This is contrary to the expected fracture behaviour as a lower GB impurity concentration is assumed to have a larger GB fracture toughness and therefore transgranular fracture should happen more often. Figure $3-\mathrm{b}$ shows the SEM image of a recrystallized tungsten material with an overlay of a $\mathrm{P}$ mapping. The mapping shows clearly that $\mathrm{P}$ is covering most of the GBs, however, the weakening-effect on the GB is not as pronounced as to just obtain intergranular fracture. The corresponding spectrum in figure 3-a indicates $\mathrm{P}$ as the only impurity at the GBs. As the recrystallized materials produced from the former single crystal ( $\mathrm{W}_{600}^{\mathrm{sc}}, \mathrm{W}_{800}^{\mathrm{sc}}$ and $\mathrm{W}_{1200}^{\mathrm{sc}}$ ) show different fractions of inter- and transgranular fracture and impurities do not play a role in these cases, it is obvious that factors like size and shape of the grains, which will be discussed in the following section 4.2 , play a more significant role for the cleavage of GBs or grains.

Another material with a relatively high number of GBs, depending on the degree of deformation, is $\mathrm{W}_{\text {rolled. }}$ The rolling deformation of the material leads to elongated grains and therefore a high density of GBs, although far fewer than for the UFGmaterials. The impurities are widely distributed on the relatively high density of GBs, which decreases their weakening-effect and therefore transgranular fracture should be preferred. While cleavage fracture was found beside $\sim 70 \%$ intergranular fracture along the axis of the rod, transgranular fracture is the dominant type in the case of crack propagation perpendicular to rolling direction. Although $\mathrm{P}$ was found on several GBs, which can be seen in the spectrum of figure 2 -c, its weakening-effect on the GBs is rather limited and does not force a crack to propagate just intergranularly although a lot of GBs are available due to the elongated grain structure. However, instead of propagating just along the GBs, it seems much easier for a crack to cleave grains too.

The crack path is governed by the local driving force in the different propagation directions and the corresponding crack propagation resistances. The local driving force is determined by the global driving force and the local geometry of the crack. The possible crack propagation directions for cleavage crack propagation are given by the possible cleavage planes and the geometry of the grain boundaries. The resistance for cleaving the grain boundary and the resistance for cleaving the grain can depend on many parameters, for example the dislocation density. It is important to note that both crack propagation resistances depend on temperature in a different manner. This results in a change of the ratio between transgranular and intergranular fracture at different temperatures [11. For the crack propagation perpendicular to rolling direction an almost transgranular fracture behaviour is observed (figure 1-b). Due to the heavily elongated grains the crack encounters predominately GB's which are perpendicular to the macro crack propagation direction. The driving force for a $90^{\circ}$ kinked crack is significantly smaller than for the unkinked one [22]. Only for the case that the fracture resistance for the intergranular fracture is less than $\frac{1}{2}$ of the fracture resistance for transgranular fracture (in terms of stress intensity factor), a crack deflection along the grain boundaries should occur. That is obviously not the case. The weakening due to the impurities is not sufficient in the present case. The fracture experiments for the crack propagation in rolling direction indicate that the fracture resistance at room temperature is only somewhat smaller than the resistance to cleave grains, because both fracture modes are 
present.

$\mathrm{W}_{\text {sintered }}$ is a technically pure tungsten material with an average grain size of $\sim 25 \mu \mathrm{m}$. Although $\mathrm{P}$, the only detected impurity, can mainly be found in the sinter pores and is not covering the GBs (figure 4), intergranular fracture is the dominant fracture type for this material. Compared to that, $\mathrm{W}_{\text {hipped }}$, the only material with a significantly higher $\mathrm{O}$ concentration, where most of the GBs are covered by $\mathrm{O}$ as shown in figure 5 , shows a lower fraction of intergranular fracture than $\mathrm{W}_{\text {sintered }}$. Although both materials have a similar porosity and a similar grain size their fracture behaviour is quite different. This cannot be caused just by impurities especially since $\mathrm{W}_{\text {hipped }}$, the material with the higher impurity concentration, has a higher fraction of cleavage fracture as shown in table 2 . The reason for such a behaviour is probably the grain size distribution as well as the morphology which will be discussed in section 4.2 .

The investigations show that an increased number of GBs by e.g. a very fine grain structure or elongated grains, is able to distribute GB impurities widely enough to avoid an effect on the boundaries. However, the typical grain boundary impurities like $\mathrm{O}$ or $\mathrm{P}$, as they are present in the small amounts in these technically used materials or in the $\mathrm{W}_{\text {hipped }}$, do not seem to influence the crack path significantly.

\subsection{Influence of grain size}

Due to the high density of GBs in UFG-W and UFG-W'sc , impurities have no effect on the crack path. The varying fractions of inter- and transgranular fracture in the different directions of a HPT sample [17] demonstrate an effect of the shape of the grains. Such an effect can also be seen in the case of the rolled material. Most of the GBs are partly covered with $\mathrm{P}$, hence a decrease in the fracture resistance of the GBs is expected. Obviously that is not the case in the investigated material, the effect of impurities seems to be too small compared to other parameters. Compared to these materials all other investigated samples have equiaxed grains except for the $\mathrm{W}_{600}^{\mathrm{sc}}$. After recrystallizing at $600^{\circ} \mathrm{C}$ an aspect ratio and therefore a dependency on the testing direction of the sample remains. However, the samples with equiaxed grains, especially $\mathrm{W}_{800}^{\mathrm{sc}}$ and $\mathrm{W}_{1200}^{\mathrm{sc}}$ with low impurity concentrations and also $\mathrm{W}_{1200}$ and $\mathrm{W}_{\text {recryst }}$ demonstrate a very pronounced dependency of the fracture characteristic on the grain size. Table 2 clearly shows a decreasing fraction of intergranular fracture with increasing grain size. While in the case of fine grained $\mathrm{W}$ materials crack propagation along grain boundaries is favoured, in the coarse grained recrystallized materials cleaved grains are more frequently observed. The difference might be explained by the different crystal texture as the probability to find cleavage planes parallel to the macroscopic crack propagation plane is determined by the texture. Another possibility could be an intrinsic effect of the grain size on the resistances to fracture grain boundary or grain. For ideal brittle fracture such behaviour is not expected. However, in the cleavage process of tungsten a certain plasticity is involved hence such effect might be possible especially for very small grains. However, in the present case we believe that the variation of the ratio of transgranular fracture to intergranular fracture is not dominated by the mentioned effect, it is more related to the grain size distribution. In the fine grained materials there is a more sharp grain size distribution than in the coarse grained materials. In a material with equiaxed grains and small variation in grain size the crack can follow without large deviation the macroscopic crack plane along the grain boundary. In the case of a bimodal distribution of grain size, the crack has to deviate sometimes more from the crack propagation plane. To avoid this the larger grains are sometimes cleaved. 
$\mathrm{W}_{\text {sintered }}$ is a material with a relatively large grain size of $\sim 25 \mu \mathrm{m}$ and almost $100 \%$ intergranular fracture. The materials has the highest fraction of intergranular fracture while most impurities are in the pores and the GB impurity concentration is relatively low. $W_{\text {hipped }}$, a material with a similar porosity of $4 \%$, has a similar grain size but a bimodal grain size distribution and a much higher O concentration at the GBs. It is also dominated by GB fracture but has a higher amount of cleaved grains. From the production history one may imagine that $\mathrm{W}_{\text {sintered }}$ and $\mathrm{W}_{\text {hipped }}$ have a very similar microstructure. However, that is not the case, $W_{\text {sintered }}$ exhibits a well developed polycrystalline microstructure with a relatively unique grain size and a porosity of $6 \%$. $W_{\text {hipped }}$ has a similar porosity, $4 \%$, however, the grains contain a higher dislocation density as a result of the HIP process and the grain size shows a larger variation. Furthermore it is interesting to note that despite the higher impurity content of $\mathrm{W}_{\text {hipped, the fracture toughness }}$ is larger than of $\mathrm{W}_{\text {sintered }}\left(\mathrm{K}_{Q}^{\text {hipped }}=11.0 \mathrm{MPam}^{0.5}>\mathrm{K}_{Q}^{\text {sintered }}=7.9 \mathrm{MPa} \mathrm{m}^{0.5}\right)$. The reason for this surprising behaviour is not obvious, it seems that the higher roughness of the fracture surface which might be caused by the larger variation in grain size, is responsible for both, the increase of transgranular fracture and the increased fracture toughness of $\mathrm{W}_{\text {hipped. }}$. The observations indicate that grain boundary impurities do not influence the fracture behaviour of technically pure tungsten as strongly as other factors. An increased dislocation density due to an elongated grain structure, like the microstructure of $W_{\text {rolled }}$, seems to have more of a positive effect on the fracture toughness than grain boundary impurities can influence it in a negative way.

\section{Concluding remarks}

The fracture surfaces of ten tungsten materials differing in grain size, microstructure and impurity concentration were investigated by Auger electron spectroscopy and scanning electron microscopy.

1. All samples were fractured in the low temperature regime (room temperature) where the expected brittle fracture behaviour was observed with varying proportions of intergranular and transgranular fracture.

2. A strong dependence of the grain size and microstructure on the fracture behaviour was observed for materials with a low impurity concentration, technically pure tungsten materials and materials with a high impurity concentration.

3. Auger electron spectroscopy measurements show that a decreasing grain size, and hence an increasing density of grain boundaries, leads to a reduction of grain boundary impurities.

4. Fracture surface analyses of recrystallized materials with larger grain sizes and a relatively low density of grain boundaries show that certain amounts of transgranular fracture can be found for such materials despite most grain boundaries being covered with phosphorous. The same behaviour can be found for rolled tungsten with elongated grains and a relatively high amount of grain boundaries.

The experiments clearly indicate that the occurance of intergranular fracture cannot be correlated with the difference in grain boundary impurities. The fraction of transgranular to intergranular fracture is controlled by other effects, like the shape of grains, the grains size distribution, texture, dislocation density and temperature. The fracture resistance of even impurity free grain boundaries in 
(2)

\begin{abstract}
tungsten at room temperature is somewhat lower than the resistance to cleave the grain. The observed differences in impurities do not seem to change this relation significantly. A transgranular fracture therefore only occurs when the propagation of the crack along the grain boundary is sufficiently unfavourable due to geometrical reasons. The statement that the grain boundary impurities do not effect the ratio of intergranular to transgranular fracture does not mean that the impurities do not have any impact on the ductility. It might be that in the ductile regime or in deformation experiments with crack free samples the impurities which occur sometimes in islands on the grain boundaries may be responsible for a crack initiation or formation of pores on this islands. The crack propagation resistance is not affected by a small quantity of such assumed islands, as shown in this study. Therefore, only the simple occurance of grain boundary fracture in tungsten is not a hint for impurity induced embrittlement.
\end{abstract}

.

(1)

(1)

(1)




\section{References}

[1] B. Gludovatz, S. Wurster, A. Hoffmann and R. Pippan, Int. J. Refract. Met. Hard Mater. (2010) in press.

[2] P.L. Raffo, J. Less-Common Met. 17 (1969) p. 133

[3] A. Wronski and A. Fourdeux, J. Less-Common Met 6 (1964) p. 413.

[4] G.A. Geach and J.E.Hughes, $2^{\text {nd }}$ Plansee Seminar (1955) p. 245.

[5] R.I. Jaffee, C.T. Sims and J.J. Harwood, $3^{\text {rd }}$ Plansee Seminar (1958) p. 380.

[6] G.L. Davis, Nature 181 (1958) p. 1198.

[7] P.J. Burdon and G.L. Davis, Nature 185 (1960) p. 455.

[8] A.W. Funkenbusch, F. Bacon and D. Lee, Met. Trans. A 10A (1979) p. 1085.

[9] A. Joshi and D.F. Stein, Met. Trans. 1 (1970) p. 2543.

[10] J.M. Liu and B.W. Shen, Acta Met. 30 (1982) p. 1197.

[11] Tran-Huu-Loi, J.P. Morniroli, M. Gantois and M. Lahaye, J. Mater. Sci. 20 (1985) p. 199.

[12] H. Danninger, F. Knoll, B. Lux, P. Wilhartitz and M. Grasserbauer, Int. J. Refract. Met. Hard Mater. 4 (1985) p. 92.

[13] A. Vorhauer and R. Pippan, Scr. Mater. 51 (2004) p. 921.

[14] A.P. Zhilyaev and T.G. Langdon, Prog. Mater. Sci. 53 (2008) p. 893.

[15] M. Faleschini, H. Kreuzer, D. Kiener and R. Pippan, J. Nucl. Mater. 367 (2007) p. 800.

[16] Olympus Soft Imaging Solutions GmbH - analySIS pro 5.0.

[17] A. Hohenwarter and R. Pippan, Mater. Sci. Eng., A 527 (2010) p. 2649.

[18] R.W. Margevicius, J. Riedle and P. Gumbsch, Mater. Sci. Eng., A 270 (1999) p. 197.

[19] D. Rupp and S.M. Weygand, Phil. Mag. 90 (2010) p. 4055.

[20] K.D. Childs, B.A. Charlson, L.A. LaVanier, J.F. Moulder, D.F. Paul, W.F. Stickle and D.G. Watson, Handbook of Auger Electron Spectroscopy, Third Edition, Physical Electronics, Inc., Eden Prairie, Minnesota, 1995.

[21] B. Predel, Landolt-Börnstein - Numerical Data and Functional Relationships in Science and Technology; Group IV: Physical Chemistry; Thermodynamic Properties - Phase Equilibria, Crystallographic and Thermodynamic Data of Binary Alloys, vol. 5i, Springer-Verlag, Berlin Heidelberg, 1998.

[22] R. Pippan, Eng. Fract. Mech 44 (1993) p. 821. 
Tables with captions

Table 1. Main impurity elements of technically pure tungsten $(\mathrm{W}>99.97 \%$ ) manufactured by Plansee Metall GmbH. The first line shows the maximum concentration Plansee guarantees not to exceed while the second line gives the average impurity concentrations. An additional chemical analysis on $\mathrm{O}, \mathrm{P}$ and $\mathrm{S}$ was made on the investigated materials. The impurity contents are shown in the third line of the table.

\begin{tabular}{llllllll}
\hline Element & $\mathrm{C}$ & $\mathrm{H}$ & $\mathrm{N}$ & $\mathrm{O}$ & $\mathrm{P}$ & $\mathrm{S}$ & $\mathrm{Si}$ \\
\hline Guaranteed analysis $(\max ) / \mu \mathrm{g} / \mathrm{g}$ & 30 & 5 & 5 & 20 & 20 & 5 & 20 \\
Typical analysis / $\mu \mathrm{g} / \mathrm{g}$ & 10 & 2 & $<2$ & 5 & $<10$ & $<2$ & 5 \\
$\begin{array}{l}\text { Chemical analysis / } \mu \mathrm{g} / \mathrm{g} \\
\text { (investigated material) }\end{array}$ & & & & 1 & $<10$ & $<5$ & \\
\hline
\end{tabular}

Table 2. Materials investigated by Auger electron spectroscopy, their fabrication conditions and their corresponding fracture toughness (FT) values. The average grain sizes (diameter) of the materials with equiaxed grains are shown additionally. Materials with an elongated grain structure are described by the length of the major axes of the grains (l) together with its aspect ratios (UFG-W, UFG-W $\mathrm{W}^{\mathrm{sc}}$ and $\mathrm{W}_{600}^{\mathrm{sc}}$ ) or the average diameter (d) of the grains in the cross section ( $\mathrm{W}_{\text {rolled }}$ ). $\mathrm{l}_{\mathrm{GB}} / \mathrm{A}$ shows the sum of the length of high angle grain boundaries per $1 \mu \mathrm{m}^{2}$ grain boundary area while $\mathrm{f}_{\mathrm{ig}}$ lists an average proportion of intergranular fracture obtained from the fracture surfaces. Most values are listed with their standard deviations. The superscript "sc" indicates that these samples were produced from a high purity single crystal.

\begin{tabular}{|c|c|c|c|c|c|c|}
\hline Material & Condition & $\begin{array}{l}\text { Av. grain size } \\
\mu \mathrm{m}\end{array}$ & Aspect ratio & $\begin{array}{l}\mathrm{l}_{\mathrm{GB}} / \mathrm{A} \\
\mu \mathrm{m} / \mu \mathrm{m}^{2}\end{array}$ & $\begin{array}{l}\mathrm{f}_{\mathrm{ig}} \\
\%\end{array}$ & $\begin{array}{l}\mathrm{FT} \\
\mathrm{MPa} \mathrm{m}^{0.5}\end{array}$ \\
\hline $\mathrm{W}_{\text {rolled }}$ & rolled & $\begin{array}{l}121.52 \pm 35.55(\mathrm{l}) \\
31.0 \pm 9.1(\mathrm{~d})\end{array}$ & - & $1.09 \times 10^{-1}$ & $\begin{array}{l}68.4 \pm 14.1 \\
10.6 \pm 5.0\end{array}$ & $(5-15)^{b}$ \\
\hline $\mathrm{W}_{\text {sintered }}$ & sintered & $25.0 \pm 9.9$ & - & $8.36 \times 10^{-2}$ & $95.9 \pm 2.0$ & $\sim 8$ \\
\hline $\mathrm{W}_{\text {hipped }}$ & hipped & bimodal & - & $1.02 \times 10^{-2}$ & $82.5 \pm 4.2$ & $\sim 11$ \\
\hline UFG-W ${ }^{\mathrm{sc}}$ & ultra-fine grained & $0.26 \pm 0.09(1)$ & $0.43 \pm 0.27$ & $1.86 \times 10^{0}$ & $-\mathrm{a}$ & $-c$ \\
\hline $\mathrm{W}_{600}^{\mathrm{sc}}$ & $\mathrm{SPD}+1 \mathrm{~h} @ 600^{\circ} \mathrm{C}$ & $0.31 \pm 0.11(1)$ & $0.45 \pm 0.27$ & $4.07 \times 10^{0}$ & $92.0 \pm 5.3$ & $-\mathrm{c}$ \\
\hline $\mathrm{W}_{800}^{\mathrm{sc}}$ & $\mathrm{SPD}+1 \mathrm{~h} @ 800^{\circ} \mathrm{C}$ & $8.4 \pm 2.7$ & - & $3.91 \times 10^{-1}$ & $85.5 \pm 7.2$ & $-\mathrm{c}$ \\
\hline $\mathrm{W}_{1200}^{\mathrm{sc}}$ & $\mathrm{SPD}+1 \mathrm{~h} @ 1200^{\circ} \mathrm{C}$ & $92.4 \pm 30.3$ & - & $1.38 \times 10^{-2}$ & $66.1 \pm 6.6$ & $-\mathrm{c}$ \\
\hline UFG-W & ultra-fine grained & $0.33 \pm 0.13(\mathrm{l})$ & $0.49 \pm 0.18$ & $6.22 \times 10^{0}$ & $-\mathrm{a}$ & $(9-33)^{d}$ \\
\hline $\mathrm{W}_{1200}$ & $\mathrm{SPD}+1 \mathrm{~h} @ 1200^{\circ} \mathrm{C}$ & $4.4 \pm 1.5$ & - & $5.68 \times 10^{-1}$ & $87.9 \pm 2.1$ & - \\
\hline$W_{\text {recryst }}$ & $1 \mathrm{~h} @ 2000^{\circ} \mathrm{C}$ & $95.2 \pm 35.7$ & - & $3.79 \times 10^{-2}$ & $72.4 \pm 11.7$ & $\sim 5$ \\
\hline
\end{tabular}

a The amount of inter-/transgranular fracture could not be determined due to the extremely small grain sizes and also due to varying amounts in the different directions of a HPT sample [17]

${ }^{\mathrm{b}}$ The fracture toughness range is mainly dependent on the crack orientation of the samples with respect to the rolling direction [18, 19]

${ }^{\mathrm{c}}$ Due to the their microstructures and fracture morphologies the fracture toughness values are similar to technically pure tungsten in the same conditions

${ }^{\mathrm{d}}$ Values vary extremely depending on the direction of the crack propagation in a high pressure torsion sample 17 


\section{Figure captions}

(1) Fracture surfaces of tungsten materials with different microstructures investigated by Auger electron spectroscopy (AES). A rolled tungsten rod $\left(\mathrm{W}_{\text {rolled }}\right)$ with crack propagation front parallel to the axis of the rod (a) and perpendicular to the axis of the rod (b), recrystallized tungsten $\left(\mathrm{W}_{\text {recryst }}\right)(\mathrm{c})$ and sintered tungsten $\left(\mathrm{W}_{\text {sintered }}\right)(\mathrm{d})$ are technically pure tungsten materials with the average impurity concentration shown in table 1. Tungsten severe plastically deformed (SPD) by high pressure torsion (HPT) (UFG-W) (j) and tungsten deformed and additionally heat treated at $1200^{\circ} \mathrm{C}$ for an hour in a vacuum furnace $\left(\mathrm{W}_{1200}\right)(\mathrm{k})$. Hipped tungsten ( $\mathrm{W}_{\text {hipped }}$ ) which contains a much higher amount of oxygen (e). A tungsten single crystal was just severe plastically deformed by HPT $\left(\mathrm{UFG}-\mathrm{W}^{\mathrm{sc}}\right.$ ) (f), while other materials were subsequently recrystallized at $600^{\circ} \mathrm{C}\left(\mathrm{W}_{600}^{\mathrm{sc}}\right)(\mathrm{g}), 800^{\circ} \mathrm{C}\left(\mathrm{W}_{800}^{\mathrm{sc}}\right)(\mathrm{h})$ or $1200^{\circ} \mathrm{C}\left(\mathrm{W}_{1200}^{\mathrm{sc}}\right)$ (i). (The infobox on top right of each picture summarises the name, impurity content, average grain size and fraction of intergranular fracture as shown in table 2.)

(2) Auger electron spectroscopy analyses of investigated tungsten materials. AES-spectrum of a severe plastically deformed tungsten single crystal which was subsequently recrystallized at $1200^{\circ} \mathrm{C}$ for an hour in a vacuum furnace (a). The O-peak at $510 \mathrm{eV}$ represents the adsorbed oxygen after fracturing the sample in the analysis chamber. AES-spectrum of technically pure tungsten which was just severe plastically deformed (b). AES-spectrum representing technically pure tungsten rods where after a rolling deformation mainly phosphorous $(123 \mathrm{eV})$ was found at the grain boundaries (c). All spectra were taken at grain boundaries.

(3) AES spectrum of the grain boundary of $\mathrm{W}_{\text {recryst }}$ indicating $\mathrm{P}$ as the only impurity (a). Fracture surface of recrystallized tungsten with a P-mapping as an overlay showing $\mathrm{P}$ covering several grain boundaries (b).

(4) Fracture surface of $\mathrm{W}_{\text {sintered }}$ with a $\mathrm{P}$-mapping as an overlay showing $\mathrm{P}$ concentrated in the sinter pores.

(5) Fracture surface of $\mathrm{W}_{\text {hipped }}$ with an overlaying O-mapping showing $\mathrm{O}$ covering most grain boundaries. 
Figures
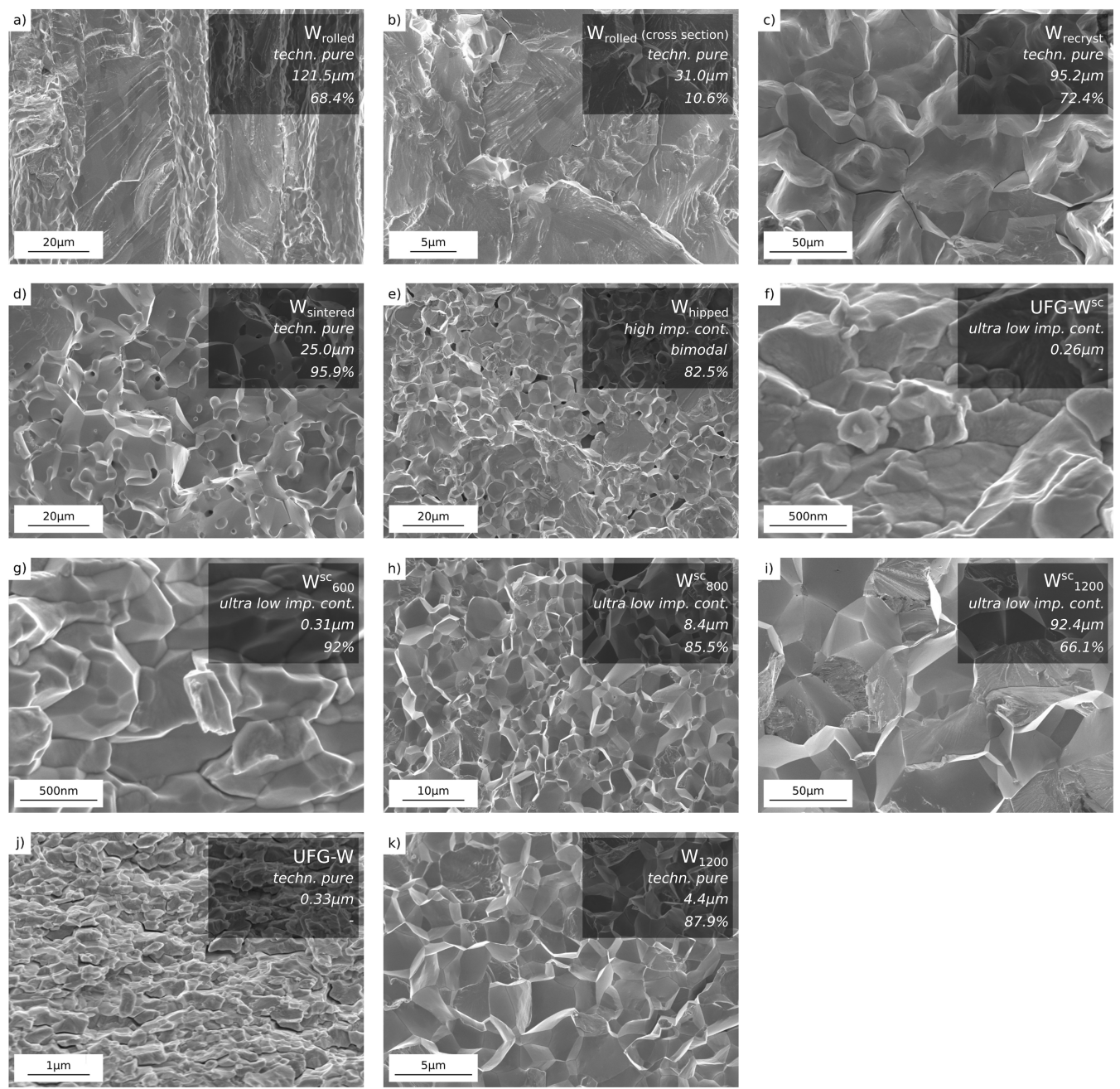

Figure 1. Fracture surfaces of tungsten materials with different microstructures investigated by Auger electron spectroscopy (AES). A rolled tungsten rod ( $\left.\mathrm{W}_{\text {rolled }}\right)$ with crack propagation front parallel to the axis of the rod (a) and perpendicular to the axis of the rod (b), recrystallized tungsten ( $\mathrm{W}_{\text {recryst }}$ ) (c) and sintered tungsten $\left(\mathrm{W}_{\text {sintered }}\right)(\mathrm{d})$ are technically pure tungsten materials with the average impurity concentration shown in table 1 . Tungsten severe plastically deformed (SPD) by high pressure torsion (HPT) (UFG-W) (j) and tungsten deformed and additionally heat treated at $1200^{\circ} \mathrm{C}$ for an hour in a vacuum furnace $\left(\mathrm{W}_{1200}\right)(\mathrm{k})$. Hipped tungsten ( $\left.\mathrm{W}_{\text {hipped }}\right)$ which contains a much higher amount of oxygen (e). A tungsten single crystal was just severe plastically deformed by HPT (UFG-W ${ }^{\text {sc }}$ ) (f), while other materials were subsequently recrystallized at $600^{\circ} \mathrm{C}\left(\mathrm{W}_{600}^{\mathrm{sc}}\right)(\mathrm{g}), 800^{\circ} \mathrm{C}\left(\mathrm{W}_{800}^{\mathrm{sc}}\right)(\mathrm{h})$ or $1200^{\circ} \mathrm{C}\left(\mathrm{W}_{1200}^{\mathrm{sc}}\right)(\mathrm{i})$ (The infobox on top right of each picture summarises the name, impurity content, average grain size and fraction of intergranular fracture as shown in table 2 

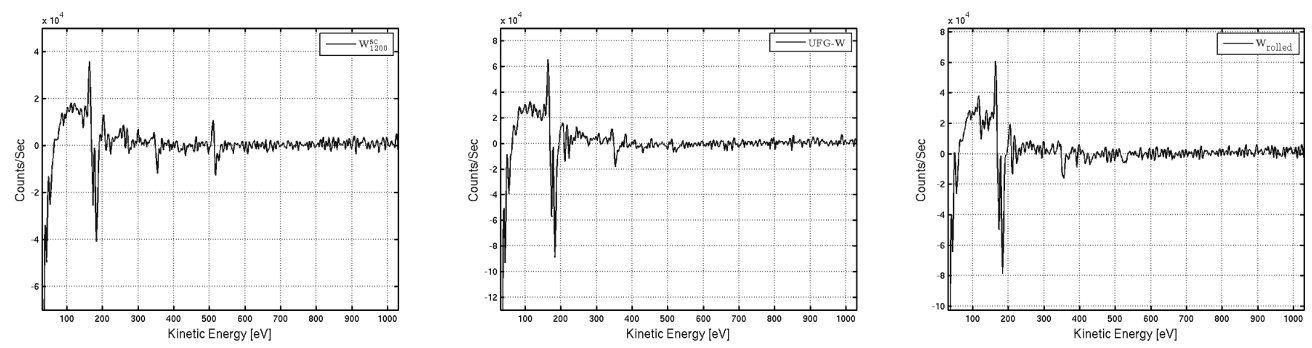

Figure 2. Auger electron spectroscopy analyses of investigated tungsten materials. AES-spectrum of a severe plastically deformed tungsten single crystal which was subsequently recrystallized at $1200^{\circ} \mathrm{C}$ for an hour in a vacuum furnace (a). The O-peak at $510 \mathrm{eV}$ represents the adsorbed oxygen after fracturing the sample in the analysis chamber. AES-spectrum of technically pure tungsten which was just severe plastically deformed (b). AES-spectrum representing technically pure tungsten rods where after a rolling deformation mainly phosphorous $(123 \mathrm{eV})$ was found at the grain boundaries (c). All spectra were taken at grain boundaries. 
3

4

5

6

7

8

9

10

11

12

13

14

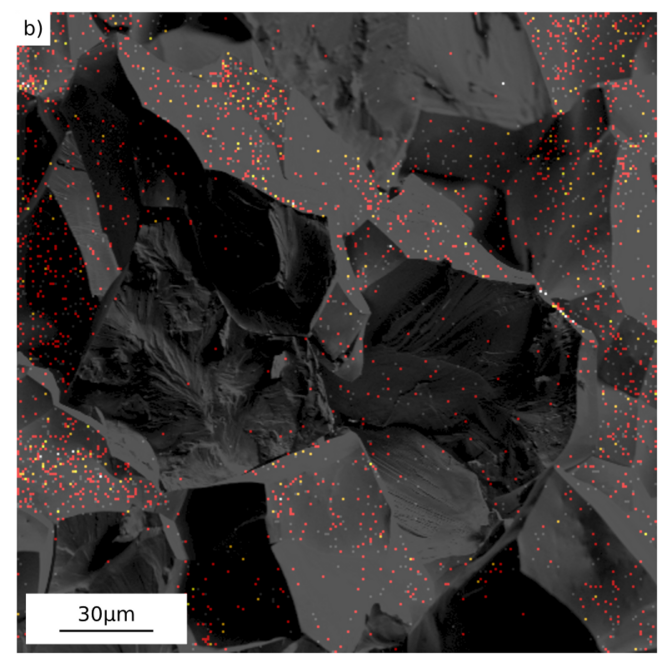

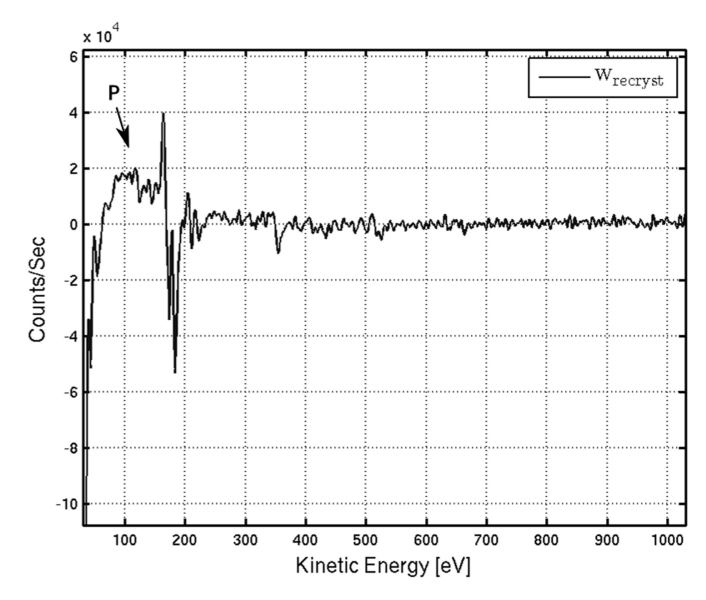
boundaries (b).

a)

Figure 3. AES spectrum of the grain boundary of $\mathrm{W}_{\text {recryst }}$ indicating $\mathrm{P}$ as the only impurity (a). Fracture surface of recrystallized tungsten with a P-mapping as an overlay showing $\mathrm{P}$ covering several grain 
Figure 4. Fracture surface of $\mathrm{W}_{\text {sintered }}$ with a P-mapping as an overlay showing $\mathrm{P}$ concentrated in the sinter pores.

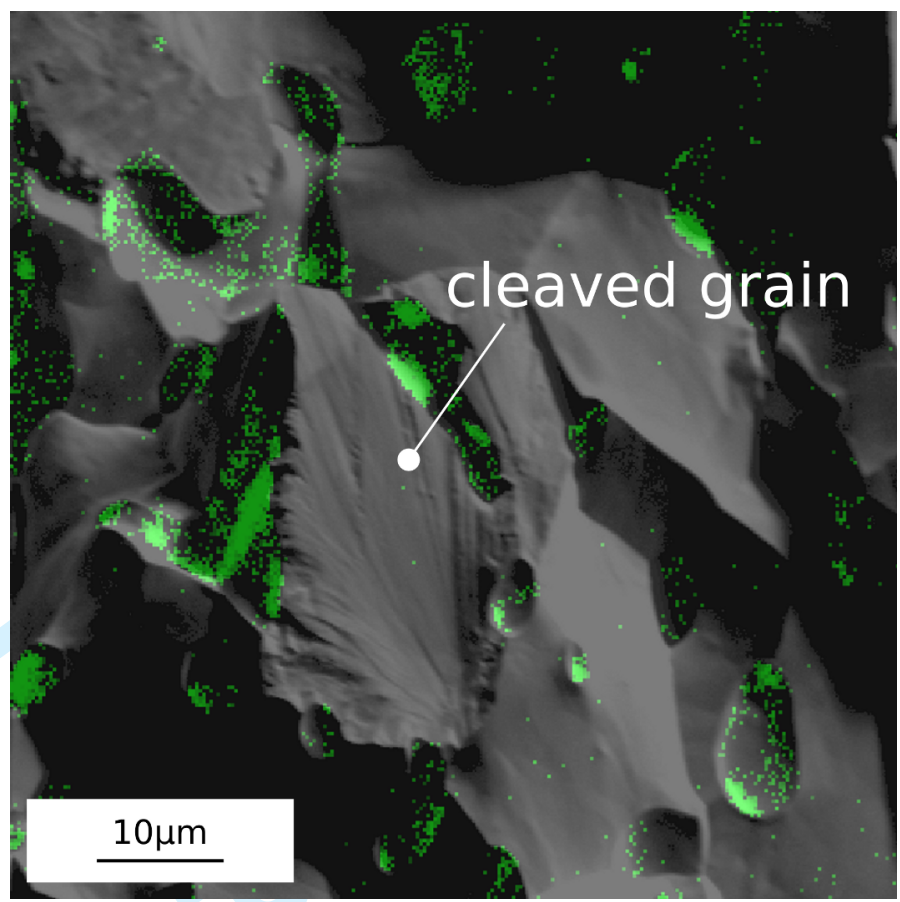


Figure 5. Fracture surface of $\mathrm{W}_{\text {hipped }}$ with an overlaying O-mapping showing $\mathrm{O}$ covering most grain boundaries.

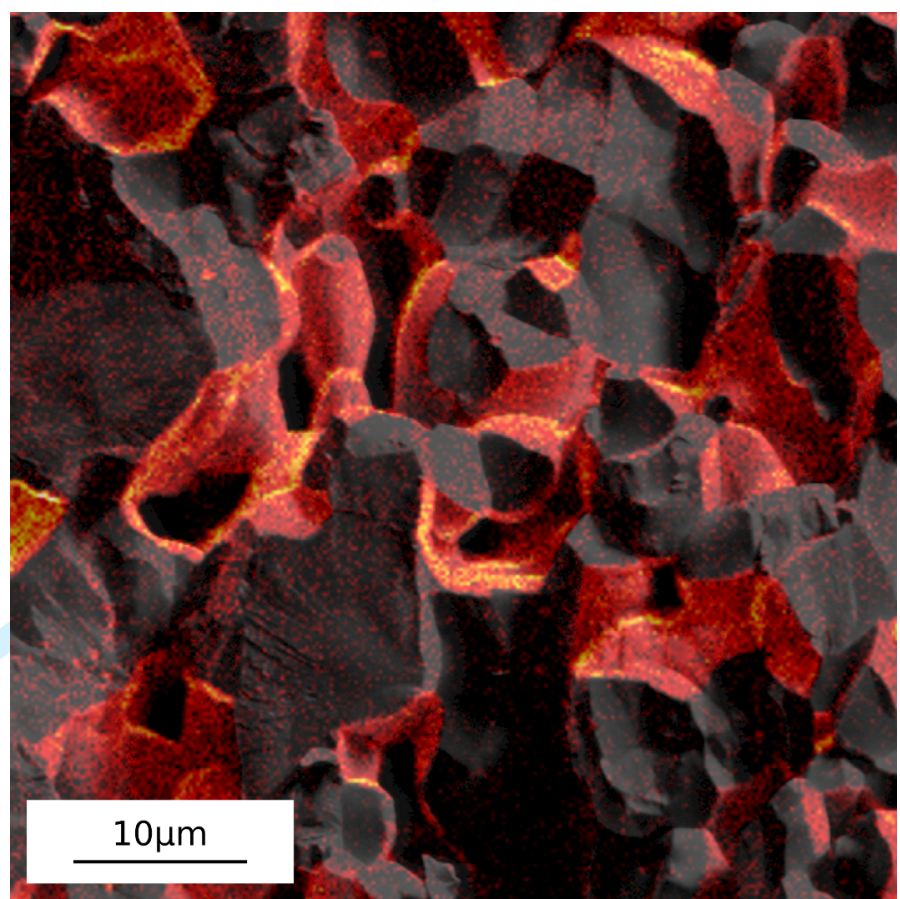

\section{Philosophical Magazine \& Philosophical Magazine Letters} REFERENCES 

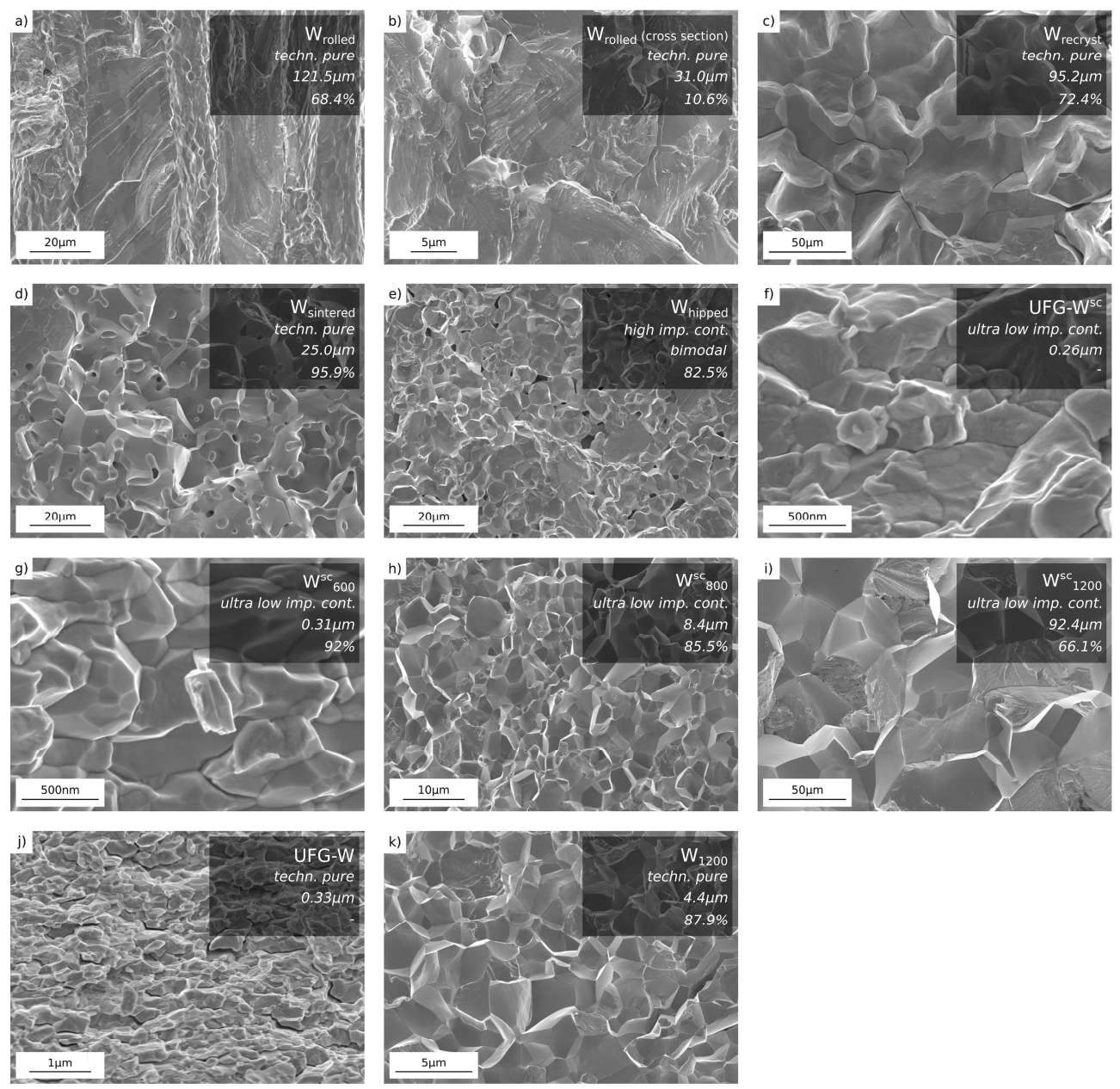


1
2
3
4
5
6
7
8
9
10
11
12
13
14
15
16
17
18
19
20
21
22
23
24
25
26
27
28
29
30
31
32
33
34
35
36
37
38
39
40
41
42
43
44
45
46
47
48
49
50
51
52
53
54
55
56
57
58
60
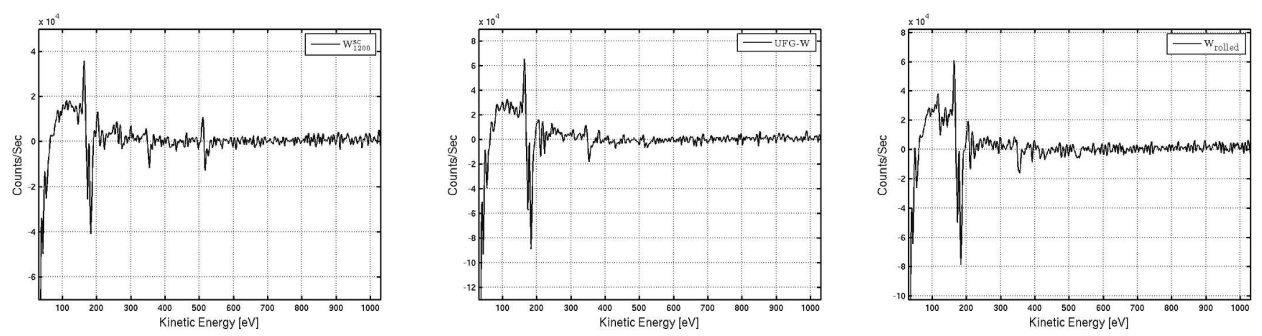

16

17

18

19

20

21

23

24

25

26

27

29

30

31

33

34

35

36

37

38

39

40

41

42

44

45

46

47

48

49

51

52

53

54

55

57

58

59

60

http://mc.manuscriptcentral.com/pm-pml 

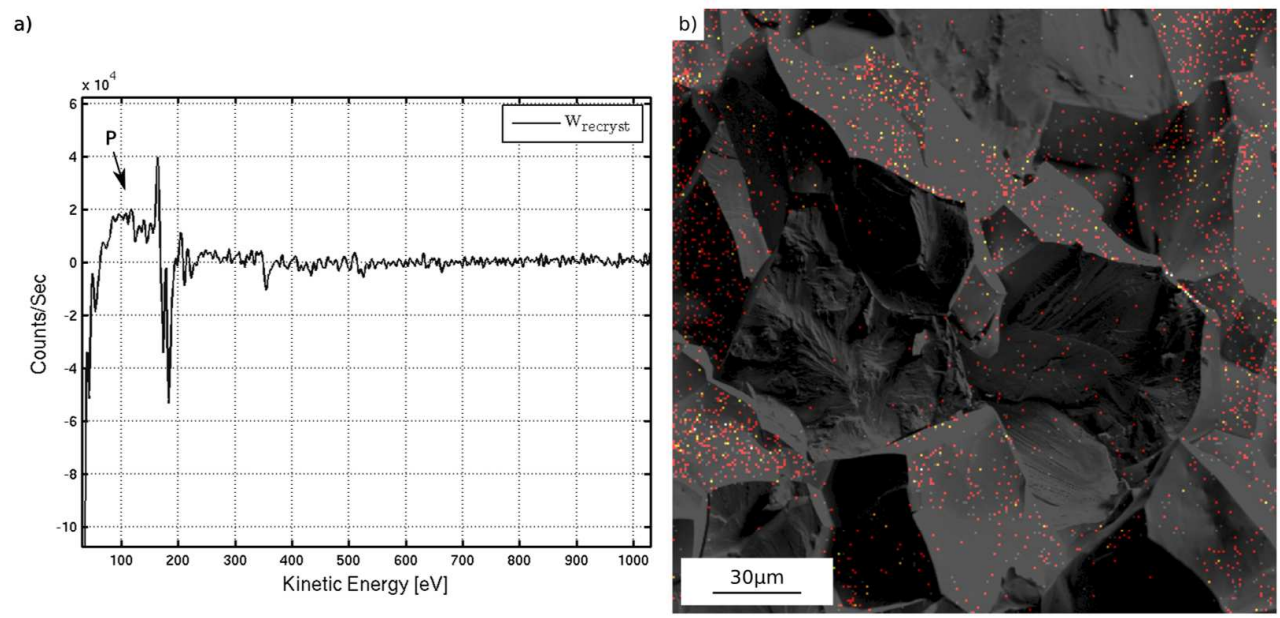


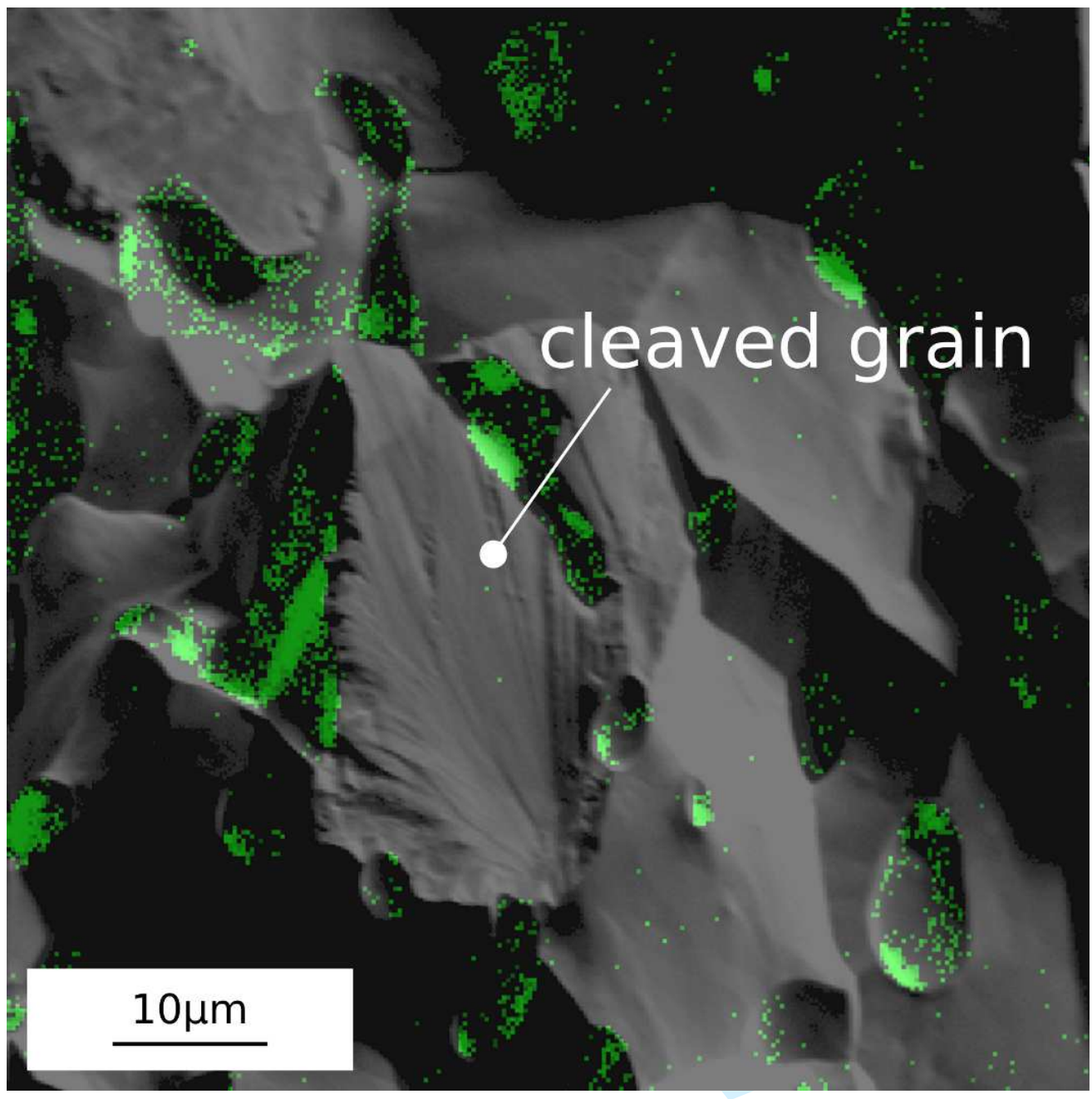




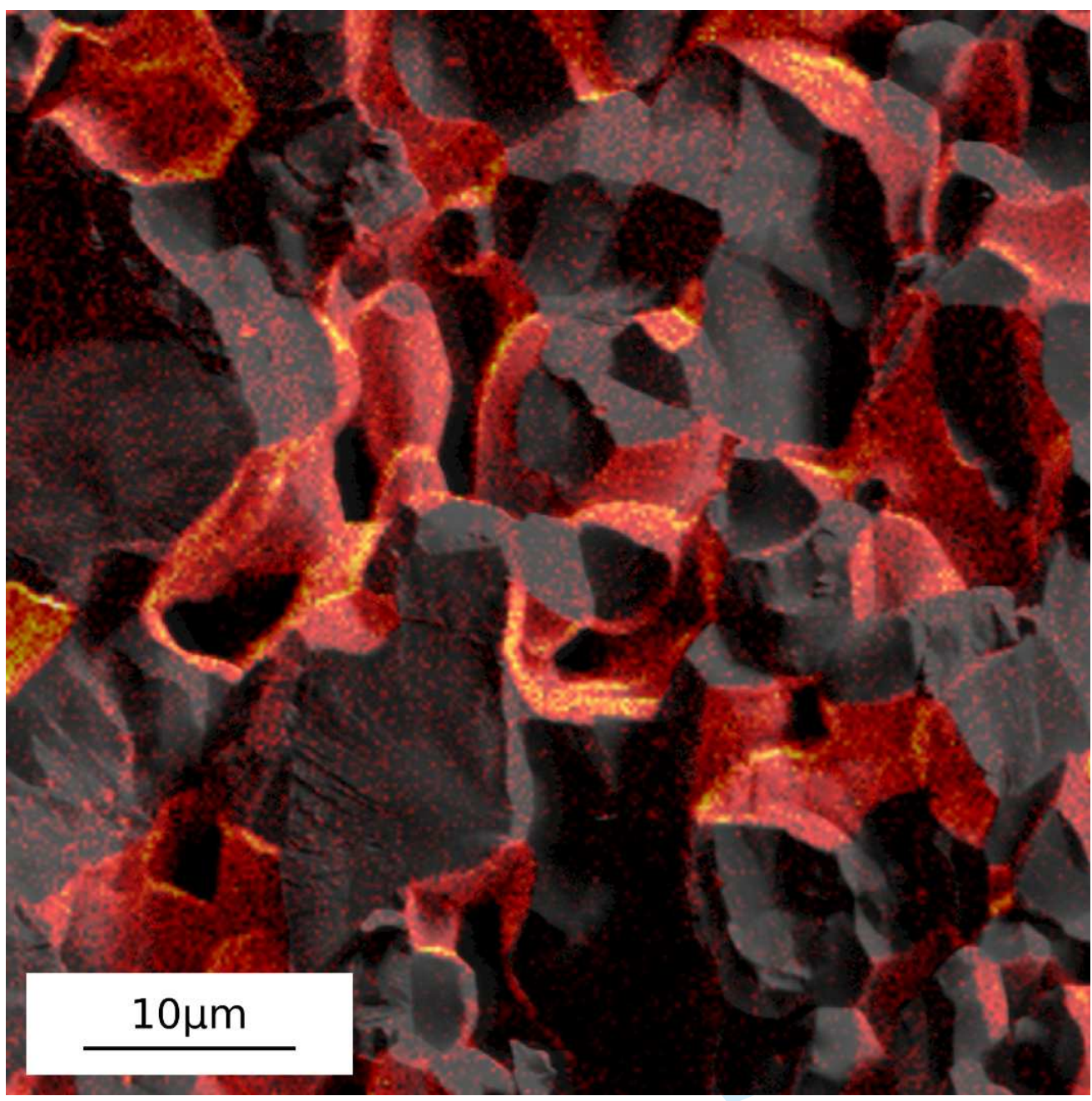

